\title{
Letter
}

\section{Chagas disease: an emerging food-borne entity?}

\author{
Alfonso J. Rodriguez-Morales. \\ Experimental Institute José Witremundo Torrealba (former Center for Parasitological Research JWT), \\ Universidad de Los Andes, Trujillo, Venezuela.
}

J Infect Developing Countries 2008; 2(2):149-150.

Received 8 January 2008 - Accepted 11 January 2008.

Copyright $@ 2008$ Rodriguez-Morales. This is an open access article distributed under the Creative Commons Attribution License, which permits unrestricted use, distribution, and reproduction in any medium, provided the original work is properly cited.

Next year will be the one hundredth anniversary of Carlos Chagas' discovery of a disease that continues to endanger the lives of a significant number of people in the Americas, despite major successes in controlling its transmission and recent achievements in experimental specific chemotherapy against its etiological agent, Trypanosoma cruzi [1]. Through its impact on worker productivity, premature disability, and death, Chagas disease accounts for 670,000 disability-adjusted life years (DALYs), making it the most noteworthy parasitic disease of the Americas [2]. Furthermore, not only does primary infection continue to endanger the lives of countless people in the region, but the chronic manifestations of Chagas disease also affect the livelihood of many individuals previously infected. As the trend for global migration increases, the scope of Chagas disease threatens to expand exponentially, from rural to urban areas and endemic to non-endemic regions [3].

In this epidemiological scenario, a relatively new element in its transmission has been added, the oral transmission. First described in Brazil in 2005 when an outbreak caused several deaths, another 15 cases of the disease followed in Santa Catarina related to the sale and ingestion of sugarcane juice [4,5]. This pattern has been continuing, confirming that oral transmission is not only possible, but more common than previously thought [5]. Since the initial report in 2005, more than a dozen outbreaks of Chagas disease have been recorded in the northern Brazilian states of Para, Amazonas, and Amapa [6]. But now, a confirmed considerable and significant outbreak of Chagas disease in Caracas, Venezuela, also related to ingestion of contaminated beverages [7], further suggests that American Trypanosomiasis is a food-borne entity.

One hundred twenty-eight positive cases were confirmed in the Venezuelan capital up to the last week of December 2007. All these cases were clustered in a municipality school [7]. From that total, 12 patients were hospitalized. Patients are receiving benznidazole, one of the approved drugs for the specific treatment of Chagas disease, particularly for acute forms cases like these. Investigations are ongoing at the school given the exposure of 956 individuals [7]. As a consequence of this outbreak, the Ministry of Health, in conjunction with other metropolitan public health, research and academic institutions, produced guidelines for the diagnosis, management and treatment of Chagas disease during the acute phase at health facilities [8].

These ongoing outbreaks in Brazil and Venezuela should serve as a warning to public health authorities and infectious disease physicians about the possible emergence of similar outbreaks related to food and beverages in other countries. Although diagnosis can be difficult because the clinical symptoms are sometimes unspecific, Chagas disease should be suspected particularly in endemic zones. In the case of the Caracas outbreak, this city is not endemic for this disease and fortunately the first case was quickly diagnosed through the finding of trypomastigotes in blood films from the first patient. It should be mentioned that in Venezuela a significant number of acute phase Chagas disease cases have been previously reported [9]. During the acute phase a chagoma, an area of inflammation at the site of 
inoculation, could be seen. If conjunctival inoculation occurs, the triad of conjunctivitis, periorbital edema, and preauricular lymphadenopathy (the Romaña sign) may occur. Systemic dispersion of multiplying parasites during the acute phase may be asymptomatic or may manifest as fever, tachycardia, malaise, lymphadenopathy, hepatosplenomegaly, edema, vomiting, diarrhoea, anorexia, and/or rash [1]. In the acute phase, parasitization of cardiac muscle and brain may cause acute myocarditis and meningoencephalitis, respectively, sometimes causing death [1]. These clinical features were seen in food-borne acute Chagas disease cases.

For these reasons, awareness and knowledge of these epidemiological pattern changes should be raised continuously both in the biomedical literature and by the public health authorities in endemic countries and in those countries with migration-related risk for Chagas disease. Chagas syndrome is a neglected disease, but it has clearly not disappeared.

\section{References}

1. Von A, Zaragoza E, Jones D, Rodríguez-Morales AJ, Franco-Paredes C (2007) New insights into Chagas Disease: a neglected disease in Latin America. J Infect Developing Countries 1:99-111.

2. Tarleton RL, Reithinger R, Urbina JA, Kitron U, Gürtler RE. (2007) The challenges of Chagas Disease-- grim outlook or glimmer of hope. PLoS Med 4:e332.

3. Franco-Paredes C, Von A, Hidron A, Rodríguez-Morales AJ, Tellez I, Barragán M, Jones D, Náquira CG, Mendez J. (2007) Chagas disease: an impediment in achieving the Millennium Development Goals in Latin America. BMC Int Health Hum Rights 7:7

4. ProMED-mail. Trypanosomiasis, foodborne - Brazil (Santa Catarina) (03). ProMED-mail 2005; 27 Mar: 20050327.0884. <http://www.promedmail.org>. Accessed 03 January 2008.

5. Benchimol Barbosa PR (2006) The oral transmission of Chagas' disease: an acute form of infection responsible for regional outbreaks. Int J Cardiol 112:132-3.

6. ProMED-mail. Trypanosomiasis, foodborne - Brazil (Amazonia). ProMED-mail 2007; 21 Aug: 20070821.2732. <http://www.promedmail.org>. Accessed 03 January 2008.

7. ProMED-mail. Enf. de Chagas, vía oral, brote escolar Venezuela (05) ProMED-mail 2007; 23 Dec: 20071224.4125. <http://www.promedmail.org>. Accessed 03 January 2008.

8. Ministerio del Poder Popular para la Salud (2007) Guía para el Diagnóstico, Manejo y Tratamiento de Enfermedad de Chagas en fase Aguda a nivel de los Establecimientos de Salud. 1st Edition. Ministerio del Poder Popular para la Salud, Caracas, Venezuela. 32 pages.
9. Añez N, Carrasco H, Parada H, Crisante G, Rojas A, et al. (1999) Acute Chagas' disease in western Venezuela: a clinical, seroparasitologic, and epidemiologic study. The American journal of tropical medicine and hygiene 60:215-22.

Corresponding Author: Alfonso J. Rodriguez-Morales, Experimental Institute José Witremundo Torrealba (former Center for Parasitological Research JWT), Universidad de Los Andes, Trujillo, Venezuela. E-mail: alfonsorm@ula.ve

Conflict of interest: No conflict of interest is declared. 